\title{
EDUCAÇÃO AMBIENTAL NO ENSINO FUNDAMENTAL: DISCUSSÃO DE POSSIBILIDADE
}

\author{
Núbia Rosa Baquini da Silva Martinelli ${ }^{1}$
}

\section{RESUMO}

Apresentamos recorte de pesquisa qualitativa sobre saberes discentes produzidos na relação entre os movimentos de ensinar e aprender na escola, com foco em construções conceituais relativas a educação ambiental. Analisamos as manifestações discentes e docentes em aula, como elemento redirecionador dos planejamentos e do curso da aula, ressignificando o ensinar e o aprender. Interações dialógicas em aulas de Ciências do 9o ano do Ensino Fundamental foram vídeo-gravadas, transcritas e analisadas, segundo a teoria das interações discursivas (BAKHTIN, 2006), utilizando o conceito de enunciação, como categoria analítica. Resultados parciais apontam construções conceituais, como: extinção das espécies; conhecimentos das populações tradicionais; contextualização local; conhecimento cotidiano; descarte de materiais e padrões de consumo.

Palavras-chave: Saberes discentes; Enunciações; Sustentabilidade.

\section{ENVIRONMENTAL EDUCATION IN PRIMARY EDUCATION: DISCUSSION OF POSSIBILITIES}

\begin{abstract}
We present a qualitative research clipping about student knowledge produced in the relation between the teaching and learning movements in the school, focusing on conceptual constructions related to environmental education. We analyze student and teacher manifestations in class, as a redirecting element of the planning and the course of the lesson, resignificando the teaching and the learning. Dialogic interactions in science classes of the 9th year of elementary school were video-recorded, transcribed and analyzed according to the theory of discursive interactions (BAKHTIN, 2006), using the concept of enunciation as an analytical category. Partial results point to conceptual constructions, such as: extinction of species; knowledge of traditional populations; local contextualization; everyday knowledge; disposal of materials; consumption patterns.
\end{abstract}

Keywords: Knowledge students; Enunciations; Sustainability. 1 Mestre (PPGEA - FURG), Doutoranda
nubia.bachini@riogrande.ifrs.edu.br. 


\section{Introdução}

Este texto discute a inserção da educação ambiental no Ensino Fundamental, valendo-se do corpo empírico e epistemológico de pesquisaação em curso. Algumas questões orientam a discussão: Onde está a educação ambiental nas práticas pedagógicas rotineiras, na escola básica? É necessário planejar atividades específicas de educação ambiental esclarecendo as intenções pedagógicas, ao tratar conceitos e relações atinentes ao meio ambiente e a sustentabilidade? Vejamos essa questão sob duas perspectivas opostas: Compreender a educação ambiental como uma especificidade no currículo escolar requer refletir sobre as formas possíveis de inseri-la ou efetiva-la no cotidiano escolar. Sendo a linguagem determinante das intencionalidades (BAKHTIN, 2006), convidamos a refletir sobre os verbos que usamos acima: Ao cogitar "inserir" a educação ambiental na educação escolar, não estaremos demarcando que ela é estranha, extemporânea, ou episódica a prática escolar? Por outro lado, desenvolver os conteúdos de ensino disciplinarmente, referenciados no contexto local, fomentando reflexões articuladas a perspectiva global, sem, entretanto, demarcar que se trata de educação ambiental, apostando que o curso das dinâmicas pedagógicas desenvolvidas dará conta do reconhecimento da mesma, pode produzir seu apagamento?

As reflexões que seguem desenham-se em torno dos questionamentos apontados acima e se propõem a localizar construções conceituais individuais e coletivas de educação ambiental em aulas de Ciências do Ensino Fundamental, em turmas do $9^{\circ}$ ano. As aulas são filmadas, transcritas e analisadas, segundo a teoria das interações discursivas de Bakhtin (2006), que considera as interações verbais na sua ocorrência concreta. A aula é o evento em foco, e a as interações verbais constituem a dialogia (BAKHTIN, 2006).

O propósito da pesquisa é encontrar indícios de construção conceitual dos estudantes, nas suas falas, oportunizadas e incentivadas no momento da interação pedagógica, onde se desenham os movimentos de ensinar e aprender dialogicamente (FREIRE, 1996), sendo sua questão principal: Como as manifestações dos estudantes, no curso da aula, podem funcionar como mediações dos processos dialógicos de ensinar e aprender para que a 
aprendizagem possa ocorrer dialeticamente? Apostamos que essas manifestações apontam a necessidade de corrigir o curso da aula e do programa de ensino, funcionando como guia para a prática pedagógica referenciada na interface dos movimentos de ensinar e aprender. $E$ a questão suleadora $^{2}$ deste texto, extraída do corpo da pesquisa, analogamente a sua questão central, é: Que indícios de construção conceitual discente, em termos de ideias para a sustentabilidade são encontrados nas interações?

Assim nenhuma pergunta dos estudantes é considerada inadequada ou fora de hora, pois o contexto da aula é fluido, como aponta Deleuze (1994): "uma aula é uma espécie de matéria em movimento. [...] cada grupo ou cada estudante pega o que lhe convém." (p. 64). Assim cada estudante é responsavel pelas suas elaborações e reelaborações cognitivas, ressignificando conhecimentos, num esforço de aprendizagem, individual e coletivo (VYGOTSKY, 2001).

\section{Desenho metodológico}

A pesquisa é qualitativa, exploratória, e desenvolve-se em duas escolas municipais de ensino fundamental (EMEF) da cidade do Rio Grande, RS, da qual trazemos nesse artigo analise sobre as interações havidas em três aulas numa dessas escolas, no $9^{\circ}$ ano, no turno diurno vespertino, com estudantes na faixa entre 14 e 18 anos.

Nosso objetivo pedagógico é que os estudantes insiram-se em movimentos de aprender, elaborando autonomamente conhecimentos, partindo do ensino planejado e que nas interações esses indícios de aprendizagens discentes sirvam para subsidiar as ações docentes. As práticas são propostas no sentido de estimular, constituir e manter relações dialógicas entre ensinar e aprender, e entre quem ensina e quem aprende, pois segundo Freire (1996), Carr e Kemmis (1998) e Demo (1997) entre ensino e pesquisa ha/deve haver uma relação necessária. Mas é importante pontuar que ela não é automática.

A pesquisa-ação segundo Carr e Kemmis (1988) é a modalidade que conduz a investigação, pois fundamenta a pesquisa do docente na sua própria

\footnotetext{
${ }^{2}$ Este é o termo que usamos no sul do Sul, para representar uma direção preferencial, reivindicando a perspectiva de valorizar nossa própria posição no mundo, na relação global sulnorte.
} 
prática e entende que professoras(es) da escola devem pautar seu fazer docente pela pesquisa. $O$ diálogo é categoria fundamental nessa reflexão. Para Bakhtin (2006) o sentido da palavra é determinado por seu contexto e o "dialogo constitui um caso particularmente evidente e ostensivo de contextos diversamente orientados. Os contextos não estão simplesmente justapostos, como se fossem indiferentes uns aos outros; encontram-se numa situação de interação e de conflito tenso e ininterrupto" (BAKHTIN, 2006, p. 109). Este é conflito cognitivo, existe uma vez que estão em interação pessoas, com suas circunstâncias, individualidades, propósitos e saberes. É, portanto, conflito entre diferentes, porém não entre antagônicos (ZITCOSKY, 2017). É conflito generativo de compreensões mais potentes sobre a vida dos seres naturais e sociais, em interação. É conflito pedagógico entre o que ja se sabe e os conhecimentos novos que emergem nas interações, que faz os partícipes, tanto professor(a), como estudantes estranharem as novas informações, em relação aos conhecimentos ja construídos, como ficara claro ao longo do texto. Esse estranhamento é mote para a curiosidade ingênua ir sendo, ao longo do processo, substituída pela curiosidade epistemológica (FREIRE, 1996).

Em se tratando de construir saberes ambientais esse movimento é muito necessário porque segundo Leff (2002) "aprender a complexidade ambiental não constitui um problema de aprendizagem do meio, e sim de compreensão do conhecimento sobre o meio" (p. 217). Assim podemos dizer que se trata de um tipo de meta-conhecimento, ou conhecer sobre o conhecimento multireferenciado para a sustentabilidade, considerando a atual e as futuras gerações. Essa característica ja indica uma resposta às questões que formulamos inicialmente, que iremos tecendo ao longo do texto. A seguir descrevemos e discutimos como se deu a produção do corpo empírico da pesquisa.

\section{Interações e produção do corpo empírico-epistemológico da pesquisa}

O esforço investigativo centra-se nas interações com foco nas mediações na relação pedagógica na sala de aula, porque pensamos com Freire que "... o espaço pedagógico é um texto para ser constantemente "lido", interpretado, "escrito" e "reescrito"”. (FREIRE, 1996, p. 109, aspas e itálico no 
original) e que "O ensinar se dilui na experiência realmente fundante de aprender (Op. Cit., p. 12), não existindo docência sem discência. Assim apostamos que os indícios de aprendizagem dos estudantes dão pistas ao movimento de ensinar, que deve ser corrigido e reajustado de acordo com o que os estudantes manifestam, o que coloca o movimento de aprender como motor do processo pedagógico. Isso não quer dizer que o professor perca sua função. Muito ao contrário: o papel docente complexifica-se, pois orienta-se para fora de si, atento as muitas possibilidades de aprender.

As aulas se realizaram a partir de apresentações de seminários pelos estudantes, com temas escolhidos por eles, a partir do documentário A História do Mundo em 2 Horas $^{3}$, (COHEN, 2001), de cujas interações surgiu a necessidade de tratamos da composição das substâncias, materiais e produtos, e o seu consumo, para o que utilizamos outro documentário: A História das Coisas ${ }^{4}$ (FOX, 2007). A audição e a escrita dos áudios ocorreram sem o auxílio de softwares, pois estes não funcionaram, em função das várias vozes superpostas e outros ruídos. A abordagem CTSA (ciência, tecnologia, sociedade e ambiente) naturalmente enseja 0 tratamento das questões ambientais, que abarcam a constituição individual e coletiva dos sujeitos, conforme Leff (2002).

Para a constituição e analise do corpo empírico, usamos a categoria bakhtiniana enunciação. Assim selecionamos temas das enunciações que emergiram no ato pedagógico dialógico. As filmagens contaram com o auxílio dos estudantes, o que serviu para aproxima-los da professora-pesquisadora, ajudando a quebrar algumas barreiras interpessoais oriundas, em nossa analise, da demarcação dos lugares tradicionais de professor e de estudante. No mesmo sentido as explicações aos estudantes sobre o propósito da pesquisa, dando-Ihes ciência da importância de sua contribuição, também foi fator fundamental para a sua expressão. Além disso, filmagens atualmente são muito comuns no dia-a-dia dos jovens.

\section{Discussão de resultados}

\footnotetext{
${ }^{3}$ Disponível em: https://www.youtube.com/watch?v=eGIDxp4TNWk.

${ }^{4}$ Disponível em: https://www.youtube.com/watch?v=G7 S0mMbKiw.
} 
Apresentamos tabela que relaciona as três aulas, com seus objetivos e os temas das enunciações que emergiram. Os recursos didáticos utilizados nas aulas foram: apresentação de seminários, proposições, explicações, uso de modelo físico, uso de simulador virtual, vídeos, discussões, registros no caderno e confecção de cartazes e maquetes.

Tabela 1: Dados objetivos das aulas em analise

\begin{tabular}{|c|c|c|}
\hline Aulas & Objetivos & $\begin{array}{l}\text { Temas das enunciações relativos a educação } \\
\text { ambiental }^{5}\end{array}$ \\
\hline \multirow{3}{*}{$\begin{array}{l}1 \\
\text { Gravida } \\
\text { de (G) }\end{array}$} & \multirow{3}{*}{$\begin{array}{l}\text { Discutir os eventos que originaram as condições de } \\
\text { formação da Lua; } \\
\text { Discutir as consequências de tal evento; } \\
\text { Introduzir a noção de campo gravitacional. } \\
\text { Demonstrar evidências cotidianas da ação da } \\
\text { gravidade. }\end{array}$} & Limites astronômicos: terra, atmosfera, céu, espaço. \\
\hline & & Extinções ao longo da história \\
\hline & & Extinção da espécie humana: uma possibilidade \\
\hline \multirow{2}{*}{$\begin{array}{l}2 \\
\text { Marés } \\
(\mathrm{M})\end{array}$} & \multirow{2}{*}{$\begin{array}{l}\text { Responder questões formuladas na aula anterior } \\
\text { sobre a influência da Lua na Terra; } \\
\text { Compreender as marés como deformações na } \\
\text { crosta terrestre; } \\
\text { Discutir outros aspectos, referentes as marés, além } \\
\text { da gravidade; } \\
\text { Compreender porque em Rio Grande as marés são } \\
\text { predominantemente meteorológicas; }\end{array}$} & $\begin{array}{l}\text { Tipos de conhecimento: conhecimentos das } \\
\text { populações tradicionais }\end{array}$ \\
\hline & & $\begin{array}{l}\text { Contextualização local / } \\
\text { Conhecimento cotidiano }\end{array}$ \\
\hline \multirow{3}{*}{$\begin{array}{l}3 \\
\text { História } \\
\text { das } \\
\text { coisas } \\
\text { (H) }\end{array}$} & \multirow{3}{*}{$\begin{array}{l}\text { Compreender a origem dos produtos } \\
\text { industrializados usados do dia-a-dia; } \\
\text { Discutir os possíveis impactos ambientais da } \\
\text { produção e do descarte de materiais; } \\
\text { Discutir alternativas de descarte de materiais } \\
\text { Discutir a racionalidade que orienta a produção e o } \\
\text { consumo na sociedade ocidental. }\end{array}$} & Consumo \\
\hline & & Constituição química dos materiais \\
\hline & & Reutilização, redução e reciclagem. \\
\hline
\end{tabular}

Fonte: Autoria própria.

Passamos a seguir a análise das interações discursivas, chamando atenção para a legenda usada: $P$ para falas da professora, A para as falas dos estudantes, com os códigos referentes as diferentes aulas: $\mathrm{G}$ (aula Gravidade), M (aula Marés) e H (aula História das Coisas), dividindo o texto em subtítulos relativos aos temas das enunciações. Usamos ainda AA para diversas vozes, ou quando foi impossível distinguir o falante.

\section{Tema das enunciações: Extinção das espécies / desequilíbrios ambientais}

As apresentações de seminários pelos estudantes ensejam as interações discursivas, que inter-relacionam-se entre si, na sequência de aulas,

\footnotetext{
${ }^{5}$ Os temas destacados são analisados neste texto, enquanto que os demais são objeto de análise em outros artigos, como o que analisa as aprendizagens feitas pelos estudantes em relação a Natureza da Ciência.
} 
sendo que a aula Gravidade é desencadeada pelo seminário Formação da Lua, cujo evento desencadeador é o choque de um meteoro, de acordo com teoria amplamente aceita, veiculada no A História do Mundo em 2 Horas. Daí emergem questões sobre a extinção dos dinossauros, motivada por efeito de outro choque desse tipo e daí para extinção da humanidade, como possibilidade teórica. Explica-se que nesse sentido há duas teorias: uma é a que extinção pode ser mesmo uma possibilidade no nosso caminho, como espécie, possibilidade natural, que ocorreria de qualquer forma, como ocorreu na grande extinção do período permiano, ou a dos dinossauros, explicadas mencionada no filme. Seguindo a explicação, menciona que há outras teorias dizem que podemos ser extintos, mas por causa dos desequilíbrios ambientais que provocamos, como sociedade. O aquecimento global é um dos indícios da coerência desta teoria, que na opinião de alguns pesquisadores da atualidade se realiza como exacerbação das condições climáticas, com valores extremos de temperaturas positivas e negativas registradas pelo mundo nos últimos anos. Essas explicações geram a interrogação do estudante, em tom de confirmação:

AG3: É por causa da poluição né sora...

P: Não só a poluição em si, mas também o consumo... Nosso padrão de consumo... da sociedade nossa, ocidental.

Cria-se assim a necessidade de tratar do tema do consumo, relacionado a poluição e a degradação ambiental. Entretanto nesta aula o interesse dos estudantes foca-se na natureza da ciência e seu funcionamento, de modo que para tratar o tema do consumo na sociedade ocidental, propõe-se, após essa sequência de aulas, o documentário A História das Coisas, através do qual então surge, como tema das enunciações o consumo.

\section{Temas das enunciações: Consumo, descarte e alternativas de sustentabilidade}

Dois motivos guiaram a escolha por mais um filme como estratégia didática: a turma já estava operativa com o esquema didático: filme, buscas sobre tópicos específicos, elaboração de trabalhos, discussão e fechamento dos assuntos em aula com reflexões, desenvolvimento conceitual e registros de dados pelos estudantes. Esquema pelo qual tratam-se os temas em estudo e desenvolvem-se os assuntos, chegando-se aos conceitos, dialogicamente. $\mathrm{O}$ 
outro motivo são os poucos recursos que a escola dispõe, sendo um deles a sala de vídeo para exibição de filmes, atividade que se pode fazer com qualidade, sem interrupções aleatórias, boas acomodações para os estudantes e boa qualidade de áudio e imagem. A seguir apresentamos alguns excertos das interações dialógicas da aula 3 (História das Coisas):

\begin{abstract}
AH1: Sora a primeira coisa de cara que eu não entendo... No filme das 2 horas, que a gente estudou um monte, e fez trabalho e tal... Tinha que as substâncias são feitas nas estrelas...

AH2: Não todas né...

P: Isso! Nem todas. Na verdade, os elementos, não as substâncias. Atenção pra isso hem! Vou botar aqui no quadro... Que pelo jeito isso não ficou bem entendido... Substâncias! Elas são a reunião de elementos ok? Qual é um dos elementos importantíssimos na nossa vida, na vida toda do planeta, que não foi feito nas estrelas?... Sem ele não existiria toda a abundância de vida que há hoje...

AH2: O oxigênio sora!
\end{abstract}

Após essas falas, pontua-se a diferença conceitual entre elemento e substância, esclarecendo que as substâncias podem formar-se naturalmente; ou serem sintetizadas artificialmente, e que são a reunião de elementos, mediante ligações químicas. O que ensejou voltarmos a várias passagens do filme, que justamente trata de como as coisas que usamos no dia-a-dia são fabricadas e as consequências do seu uso e descarte. Por meio desse filme foi possível, enfim tratarmos sobre o padrão de consumo da sociedade ocidental, que ensejou reflexões sobre os seguintes tópicos: diferenças entre o consumo aqui no Brasil e nos EUA, com estranhamento dos estudantes sobre a quantidade de coisas supérfluas consumidas lá, em relação ao consumo a que estão acostumados; comparação entre a vida útil de certos produtos lá e aqui; diferença entre as substâncias que compõem os produtos lá e como eles entendem que seja a composição dos mesmos produtos no Brasil. Esta discussão abre a necessidade do tratamento interdisciplinar do tema globalização, o que não chegou a ocorrer.

Várias formas de aproveitamento de materiais foram discutidas, nas quais mencionamos os 3R (reduzir, reutilizar e reciclar), dando especial importância a redução e a reutilização. Entretanto alguns estudantes externaram posições conservadoras, do tipo:

AH8: É só o que faltava, além de tudo que a gente tem que fazer, ainda tem que separar lixo... Isso é a prefeitura que tem que fazer! 
P: Mas, (fulano) reflete comigo: a prefeitura tem obrigação sim de retirar o lixo da frente da tua casa, tem obrigação com o recolhimento, certo. Mas ela vai dentro da tua casa separar o lixo? Ah por favor né... E qual é o problema do lixo todo junto? Quem vai me responder? AH2: Ah sora, se tu pensar... é que fica tudo sujo né... Até o que não estava sujo... Antes.

P: Precisamente! Se a gente tem um PET limpinho, vazio, a gente vai botar ele numa sacola com resto de comida, pra ficar tudo sujo? Olha o volume que vai dar isso! Volume vocês já estudaram comigo. O que é volume? Vamos lembrar.

AH7: É espaço sora, espaço que a coisa ocupa. A gente viu lá antes...

$P$ : Isso! Então, quando a gente junta os lixos, além de sujar o que não era sujo, a gente forma um volume muito maior de lixo. E pra quê? Só por não separar em casa... Coisa que não é obrigação da prefeitura não. É nossa.

Motivada por essa discussão acima iniciamos conversas na escola, com o intuito de fomentar a ideia da separação dos resíduos em dois tipos: seco ou limpo e orgânico ou úmido. Foi curioso receber de alguns colegas, as mesmas respostas dos estudantes, quanto a obrigação com os resíduos. Isso nos leva a refletir que numa comunidade carente de bons serviços públicos, muito provavelmente seja necessária estratégia diferente, para desencadear processos que culminem em conscientização sobre a responsabilidade pelos resíduos, pois os profissionais e os cidadãos do bairro sentem-se já sobrecarregados, ocupando-se das próprias funções de trabalho e subsistência.

Especulando sobre esse posicionamento frente aos resíduos, pode-se inferir que esse pensamento está arraigado na comunidade, de modo que faz sentido a recomendação de Freire (1996) de partir da "experiência que têm os alunos de viver em áreas da cidade descuidadas pelo poder público para discutir, por exemplo, a poluição dos riachos e dos córregos e os baixos níveis de bem-estar das populações, os lixões e os riscos que oferecem à saúde das gentes" (p. 33). Mas não se espere respostas que configurem relações livres de conflitos; ao contrário, será um campo empírico eminentemente conflituoso, pois aí estão em contradição valores e práticas da sociedade neoliberal que fomenta o individualismo, onde o espírito comunitário não é valorizado. Entretanto pensamos com Subirats (2003) que:

A comunidade-escola não pode ficar reduzida a uma instituição reprodutora de conhecimentos e capacidades. Deve ser entendida como um lugar em que são trabalhados modelos culturais, valores, 
normas e formas de conviver e de relacionar-se. É um lugar no qual convivem gerações diversas, em que encontramos continuidade de tradições e culturas, mas também é um espaço para mudança. A comunidade-escola e a comunidade local devem ser entendidas, acreditamos, como âmbitos de interdependência e de influência recíprocas, pois [...] indivíduos, grupos e redes presentes na escola também estarão presentes na comunidade local, e uma não pode ser entendida sem a outra (p. 76).

Nessa perspectiva a escola estava, a época da formação do corpo empírico da pesquisa (2017), em processo de construir a versão escolar local da proposta Escola ComVida ${ }^{6}$ construída pela Secretaria Municipal de Educação (SMED). Uma das iniciativas institucionais na escola, desse projeto é a criação de um grupo de artesanato, que utiliza materiais separados dos resíduos, o que aproveitamos como argumentação na interação com os estudantes, para instalar a reflexão de que, a despeito das obrigações do poder público e do direito dos cidadãos de cobrarem a realização desses direitos, iniciativas articuladas dos cidadãos podem ter bons frutos, diminuindo a quantidade de resíduos e gerando renda.

A partir dessas reflexões foram surgindo, nas interações dialógicas em sala de aula, outros exemplos de aproveitamento de materiais, tais como 0 revestimento das casas, no bairro, com caixas tetrapak ${ }^{7}$ e uma composteira construída e cuidada por moradores de uma certa quadra do bairro. Desta forma os diálogos propiciaram a revisão de conteúdos estudados em anos anteriores, como a decomposição e os ciclos naturais de matéria e energia, relacionando-os com os conceitos de elemento e substância, focos iniciais da aula 3 (História das Coisas). Entretanto, alguns estudantes manifestaram-se sempre resistentes a concordar que as iniciativas populares, no bairro pudessem ter algum valor.

Discutiu-se também o apagamento desses conhecimentos na via cotidiana. Mas lembrou-se que as redes de TV aberta apresentam esquetes (curtas inserções) durante a programação, sobre, no dizer dos estudantes: "temas da Natureza, reciclagem e essas coisas...". Ao que se explica que isto se deve a obrigação das empresas de comunicação tem no Brasil, bem como

\footnotetext{
${ }^{6}$ Disponível em: http://www.riogrande.rs.gov.br/smed/wpcontent/uploads/2013/04/PROJETO+SMED+2013.pdf

${ }^{7}$ Caixas de leite e sucos, cuja parte interna é revestida de película metálica que, colocada sobre o revestimento da casa reflete a radiação solar, conferindo conforto térmico a construção.
} 
de todos, de promover a educação para a sustentabilidade. Ao que alguns estudantes questionam como o governo pode ter ingerência sobre a programação das redes privadas. Explicamos então que para a sociedade funcionar há normas seguidas por todos e que as atitudes pessoais devem atender aos interesses sociais, dando alguns exemplos cotidianos. Encarra-se essa parte das discussões com a indicação de que os estudantes leiam o artigo $5^{\circ}$ da Constituição Federal, que trata das garantias dos cidadãos e das prioridades da nação. Consideramos que foi uma possibilidade de tratar da formação de cidadania, que não foi aproveitada em todo o seu potencial, pois estas discussões deveriam ter sido ampliadas, o que acabou não ocorrendo. 0 que nos leva a refletir sobre o espaço-tempo da escola tradicional, oriundo de modelos empresariais, onde se perdem oportunidades de desenvolver de forma integrada e contextualizada os movimentos de ensinar e aprender, embora a escola esteja em movimento inicial, no sentido de uma educação contextual.

Outro tema que motivou os estudantes ao debate nesta aula foram os venenos que são usados, ou se formam nos processos de fabricação dos materiais de uso cotidiano, em cujas discussões, a maioria mostrou-se preocupada com a saúde pública, enquanto uma minoria demonstrou estranhar o tratamento desses temas que eles não consideram "matéria de aula", em que pese as explicações sobre abordagem CTSA, dos conteúdos.

\section{Tema das enunciações: Conhecimentos das populações tradicionais}

Ao tratar do regime de marés na praia do Cassino, na aula 2 da sequência (Aula Marés) menciona-se em linhas gerais o regime de ventos na região e suas consequências, o que gera a discussão sobre diferentes saberes, conforme excerto abaixo:

P: ... Então os efeitos mais dominantes aqui [nas marés] são as condições climáticas ou meteorológicas: o vento, se é Sul, que da ressaca na praia; se é Nordeste, o mais comum aqui, que traz chuva em 3 ou 4 dias... Por causa da pressão atmosférica, que na verdade é quem manda no vento.

AM4: Ah esta sora! Tu acredita nisso do vento que traz chuva? Isso é história de pescador... Dos antigos...

P: Acredito! Sem dúvida alguma: começa a cuidar que tu vais ver que é bem assim mesmo. E o vento sul limpa o tempo, leva as nuvens embora porque a pressão atmosférica, que estava baixa, sobe. Aliás, 
esse é um conhecimento das populações tradicionais (...) como os pescadores, que observam a Natureza, que vivem da Natureza, que a Ciência está considerando agora. (...) Estão entendendo (...) que não existe só um tipo de saber, que é legal é a gente integrar os saberes. AM4: Sora! Sora tu é uma chave! Sora tu sabe essas coisas todas e tu quer ensinar pra nós... E tu também acha que o que os véio sabem é... Também valem... Eu não entendo...

De acordo com Arroio (2013) "O percurso escolar nos vai distanciando de nossas experiências e de nossas leituras do real, aprendidas nas origens" (p. 126). Assim a experiência discente se encontra, nessa perspectiva que trabalhamos, talvez confusa, pois ao fomentarmos a integração de saberes, valorização aqueles locais e seus detentores, criamos um contrate com o que eles esperam da escola. Encontram-se assim num limbo entre a cultura escolar que os acostumou a distanciarem-se dos saberes originários; e uma proposta que valoriza esses mesmos saberes e enfatiza sua importância. Segundo Diegues (2008): "Na concepção mítica das sociedades primitivas e tradicionais existe uma simbiose entre o homem e a natureza, tanto no campo das atividades do fazer, das técnicas e da produção, quanto no campo simbólico" (p. 63). O autor coloca que essa concepção mítica é mais perceptível em populações específicas, como os indígenas, entretanto também se verifica, de forma menos evidente em algumas populações ribeirinhas amazonenses e caiçaras. De nossa parte, especulamos que aqui na cidade do Rio Grande ela está ainda mais diluída nas comunidades de pescadores artesanais, ou em remanescentes, entre a geração mais velha.

Assim em se tratando do conhecimento escolar, como preparação dos estudantes para a de construção presente e futura de uma racionalidade ambiental para a sustentabilidade, é importante que eles entrem em contato com novas formas de conceber o conhecimento valido, pois, segundo Diegues (2000) em níveis superiores de ensino o desafio estará posto, como forma de efetivar praticas conservacionistas. "Para tanto, deve ser criada uma nova aliança entre os cientistas e os construtores e portadores do conhecimento local, partindo de que os dois conhecimentos - o científico e o local - são igualmente importantes (DIEGUES, 2000, p. 42). Trata-se de valorizar o conhecimento empírico da população tradicional, sendo um dos aspectos que integra a complexidade da Educação ambiental, que deve, segundo Reigota (1996) propor: "a noção de responsabilidade, não só com o planeta e a 
comunidade, mas consigo próprio..." (p. 46), enfatizando a ideia de agir na comunidade, tendo em vista a perspectiva global. Diante do exposto, consideramos que estamos fazendo nosso papel docente de desacomodar os estudantes das suas certezas de que o conhecimento valido vem exclusivamente de fontes externas a sua comunidade, ajudando a desvelar uma das condições de opressão de que padecem as classes populares (FREIRE, 1996).

ARROIO (2013) diz que os sistemas escolares ignoram o real vivido, privilegiando o real idealizado, baseado em conceitos, em nome de uma "paz cientificista e conceitualista nas escolas" (p. 127). Entretanto casos de violência e desrespeito de que se tem notícia na escola cotidianamente, derrubam a ideia dessa pretensa paz. Por isso o autor recomenda projetos pedagógicos que fomentem experiências sociais, na intenção de romper com essa lógica pedagógica anacrônica e deslocalizada. Grün (2007) fala da "ausência de historicidade [na educação] e a atividade humana colocada na perspectiva de um presente puro, liberto da tradição, considerada nefasta pela ciência" (p. 29), presente nos currículos escolares e nas ciências. E questiona:

Como poderíamos pensar questões tão fundamentais como o
desenvolvimento sustentado (que depende de uma ética para com as
futuras gerações), e a preservação das culturas tradicionais indígenas
(que depende de um respeito para com a tradição e o passado) em
um currículo cuja base conceitual está atrelada a uma férrea lógica-
presenteísta? (GRÜN, 2007, p. 108, parênteses no original).

Assim parece que a escola, em termos gerais, não tem considerado as condições sociais, ou o espaço-tempo vivido, o seu contexto. Desta forma, se pode compreender ideias apresentadas por alguns estudantes, sobre esta forma "diferente" de conduzir os processos de ensinar e aprender:

A16: Ta louco! Eu nunca tinha aprendido assim... É copiar e pronto. $P$ : Ah bom, temos um conflito aqui então... Porque eu não concordo com esse método de copiar e pronto. Por tudo o que eu tenho estudado de educação... Esse método da cópia... Não funciona... Vocês não aprendem de fato... Memorizam informações... Só. Não conseguem transformar essas informações. Unir os conhecimentos, num todo...

A16: (...) Eu acho que aula é aula. Normal... Bota no quadro, copia e pronto.

Num âmbito maior do que a própria educação, teoria e prática devem estar em conexão, dialeticamente, partindo do mundo vivido, conforme Bakhtin 
(2006), que aprofunda a questão das condições para a formação do pensamento, subordinando-o ao sistema ideológico onde ele se forma.

\section{Tema das enunciações: Contextualização local}

A contextualização espacial abre a possibilidade de o estudante ter uma experiência de aprendizagem referenciada na sua localidade, onde as experiências cotidianas ocorrem, sendo esta uma condição para a produção de sentido, ideia corroborada pela teoria sociointeracionista da aprendizagem de Vygotsky (2001). Reigota (1996) recomenda que "Na educação ambiental escolar deve-se enfatizar o estudo do meio ambiente onde vive o aluno, procurando levantar os principais problemas da comunidade, as contribuições da ciência, os conhecimentos necessários e as possibilidades concretas para a solução deles" (p. 27). Assim a contextualização torna-se ferramenta essencial para desenvolver no estudante a compreensão de si mesmo como parte do ambiente e enseja o desenvolvimento de suas potencialidades de atuação no meio social. Nessa perspectiva, emerge no final da aula 1 (Gravidade), o seguinte questionamento de um dos estudantes, o que enseja o planejamento da aula 2 da sequência (Marés): "Sora é verdade que a lua influi no mar? Na maré, ou isso é bobagem?"

Abaixo trazemos enunciações relativas a esta aula (Marés), planejada em função dessa pergunta, onde a contextualização é trabalhada num sentido crescente desde o questionamento do estudante sobre se está se falando de uma situação vivenciada na praia que ele frequenta:

P: Vamos pensar o seguinte: quem ja passou um dia todinho na praia, chegando bem cedo e indo embora bem a tardinha?

AAM: Eu, eu sora, eu fui ja muito...

A2: Sora eu vendo bolinho de peixe na praia com o meu tio, a gente passa todo todinho o dia... Mas... Eu nunca vi... Como assim, maré? Eu nunca prestei atenção... nisso da maré...

AM3: Ai guri!... Tu nuca viu que as vezes a agua ta la em cima nas dunas, e as vezes ela ta la bem longe?...

AM4: Mas não disso que tu ta falando né sora?

$\mathrm{P}$ : Na verdade sim! É disso mesmo que tô falando: quando a agua ta la nas dunas é a maré alta. Quando ela ta recuada, deixando a praia bem grande, bem larga, é a maré baixa. Mas aí é que ta: quando a agua ta la em cima, nas dunas, a razão, a causa dessa maré alta, altíssima é meteorológica, não lunar. As marés lunares, aqui em Rio Grande, são menores.

O excerto acima vemos, os temas das enunciações conhecimento 
cotidiano e contextualização local, que se constitui como eixo dessa aula, na qual os estudantes vão tomando consciência de que a "sua praia" é um ambiente no qual se pode aprender conceitos e conteúdos científicos, tais como: Gravidade; Estados de agregação da matéria (sólido, líquido e vapor); Fluidos; Deformação; Partes do planeta; Nomenclatura cientifica; Ângulos; Fenômenos cíclicos; Aspectos geográficos: (Plataforma continental, relevo, Pontos cardeais, Polos terrestres); Volume; Pressão atmosférica; Influência da pressão nas mudanças de fase; Teorema de Stevin; Grandezas vetoriais características dos vetores. Esses foram os conteúdos e conceitos trabalhados nessa aula. Entretanto muitos outros conteúdos científicos podem ser trabalhados, usando a praia como eixo orientador das reflexões e contexto.

\title{
Palavras finais
}

Com Freire (1996) apostamos na problematização a partir do vivido, como leituras de mundo dos estudantes, e no diálogo como método pedagógico, entre professores e estudantes e destes com os objetos de conhecer, na busca do "ser mais do educando" (FREIRE, 1996), a partir da consciência da própria inconclusão, comum entre professores e estudantes, como mostramos no excerto abaixo:

\begin{abstract}
AG1: Mas tu não vai pedir pra gente botar na prova tudo tudo isso aí que tu ensinou hoje né sora? Como é que eu vou decorar isso sora? P: (...) Mas não é pra vocês se sentirem... Sem condições de aprender. Ao contrario: a gente é uma turma, a gente tenta ser, fazer uma comunidade de pessoas que aprende junto... Não é pra se estressar... A sora também aprendeu pra fazer essa aula com vocês, fui pesquisar, e aprendi também na hora da aula... E assim é com a vida também: tem um monte de desafios que esperam a gente!

(...) AA: Mas sora, hoje a gente entendeu tudo... Mas no dia da prova... Não vai ter filminho do simulador... E também tu não vai deixar a gente acessar... Né?... Ai eu não vou me formar soraaaa...

(...) AA: Sora: a gente ta preocupada! A gente nunca aprendeu tanta coisa assim... A gente só copiava...

P: Hum... Falamos disso na próxima aula, mas se tranquilizem! Acalmem o coração. (Abraço entre as estudantes e a professora).
\end{abstract}

Se a consciência da própria inconclusão ou inacabamento, pedagogicamente considerada leva ao exercício da busca pelo conhecimento; em contrapartida traz uma certa angústia, que deve ser trabalhada, no sentido de tranquilizar os estudantes, para que se sintam impulsionados a conhecer e seguros das suas potencialidades. Talvez pela primeira vez as estudantes 
estejam experimentando a sensação da vastidão do conhecimento e das suas próprias limitações para conhecer. Somente por esse resultado, teria valido esta experiência pedagógica aqui discutida. Outo resultado do exercício da educação dialógica que propomos é que os estudantes se sentem autorizados a criticar o modelo de ensino proposto e efetivado, como se pode perceber no excerto acima, entre outros. Assim os excertos selecionados não apresentam apenas aspectos positivos, ou seja, a construção conceitual desejada, dentro da concepção de educação para a sustentabilidade do ambiente, que envolve a emancipação dos sujeitos. Ao contrário, algumas falas ilustram concepções que ser quer superar e que esperamos superar através do diálogo respeitoso com os estudantes em aula, através de uma pedagogia que instiga a duvidar e questionar.

A essa altura estamos em condição de responder a alguns dos questionamentos iniciais: pensamos que os estudantes devem ser comunicados claramente das intenções docentes, explicando que se está, ao tratar dos conteúdos escolares, teorizando-praticando, sobre temas da educação ambiental, uma educação para a emancipação do sujeito e das coletividades humanas e para a conservação do meio natural. Essas intenções devem ficar claras, não apenas através das práticas adotadas; mas através do discurso pedagógico. Nesse sentido pensamos que as interações serviram para dar ciência aos estudantes de que eles participaram num movimento de mudança das práticas escolares. Pensamos que esta comunicação é um movimento importante, porém não temos notícia de que ele ocorra extensivamente. Entretanto esperamos ter demonstrado que se pode promover movimentos de ensinar e aprender dialógicos e emancipadores na educação básica. E esperamos ainda que a sua divulgação possa funcionar como motivação para a ação docente transformadora, em oposição as dinâmicas da educação bancaria.

\section{Referências}

A História das Coisas, Story of Stuff (Original). FOX, L. Documentario, 21 minutos.

EUA< 2007.

Disponível

em: https://www.youtube.com/watch?v=Q3YqeDSfdfk. Acesso: 30 jul.2017.

A História do Mundo em 2 Horas. History Of The World In Two Hours (Original). COHEN, D. 120 minutos, documentario, History Chanel: 2001. Reino Unido. 
Formato digital: Disponível em: https://www.youtube.com/watch?v=tnVUJjhc4lc. Acesso: 30 mar.2017.

ARROYO, Miguel. Currículo, território em disputa. 5aed. Petrópolis: Vozes, 2013.

BAKHTIN, Mikhail. Marxismo e Filosofia da Linguagem. $7^{a}$ ed. São Paulo: Hucitec, 2006.

CARR, Wilfred e KEMMIS, Stephen. Teoría Crítica de la Enseñanza. Trad. J. A. Bravo. Barcelona, Martínez Rocca: 1988.

DELEUZE, Gilles Abecedario de Gilles Deleuze. Entrevista a Claire Parnet, 1994. Disponível em: http://escolanomade.org/wp-content/downloads/deleuzeo-abecedario.pdf. Acesso: 23 jun.2016.

DEMO, Pedro. Educar pela Pesquisa. Campinas: Autores Associados, 1997.

DIEGUES, Antônio C. Etnoconservação da natureza. (Org.) In: Etnoconservação: novos rumos para a proteção da natureza nos trópicos. 2를. São Paulo: Hucitec e NUPAUB, p. 1-46, 2000.

DIEGUES, Antônio C. O mito moderno da natureza intocada. São Paulo: NUPAUB - Núcleo de Apoio à Pesquisa sobre Populações Humanas e Areas Úmidas Brasileiras - USP/Hucitec, 2008.

FREIRE, Paulo. Pedagogia da Autonomia. São Paulo: Paz e Terra, 1996.

GRÜN, Mauro. Ética e educação ambiental: a conexão necessaria. 11ed. Campinas: Papirus, 2007.

LEFF, Enrique. Epistemologia ambiental. $2^{\text {a }}$ ed. Trad. Sandra Valenzuela. São Paulo: Cortez, 2002.

REIGOTA, Marcos. O que é educação ambiental. 1aㅡ reimp. São Paulo: Brasiliense, 1996.

SUBIRATS, Joan. Educação: responsabilidade social e identidade comunitaria. In: GÓMEZ-GRANELL \& VILA (org.). A cidade como projeto educativo. Porto Alegre: Artmed, 2003.

VYGOTSKY, Lev. Pensamento e Linguagem. Edição Ridendo Castigat Moraes. Versão para eBook. eBooksBrasil.com. 2001. Fonte Digital: www.jahr.org.

ZITCOSKI, Jaime. Educação popular e movimentos sociais na América Latina: o desafio da participação cidadã. Educação | Santa Maria | v. 42 | n. 1 | p. 7384 | jan./abr. 2017. ISSN: 0101-9031 http://dx.doi.org/10.5902/1984644420447. 